\title{
CHANGES IN THE CONCENTRATION OF UNCONJUGATED OESTRONE, OESTRADIOL-17 $\propto$ AND OESTRADIOL-17 $\beta$ IN THE MATERNAL PLASMA OF THE PREGNANT COW IN RELATION TO THE INITIATION OF PARTURITION AND LACTATION*
}

\author{
H. A. ROBERTSON \\ Reproductive Physiology Section, Animal Research Institute, \\ Ottawa, Canada
}

(Received 4th December 1972)

\begin{abstract}
Summary. The changes in concentration of unconjugated oestrone, oestradiol-17 $\alpha$ and oestradiol-17 $\beta$ have been measured in the maternal jugular venous plasma of pregnant cows over a period from 40 days before to 6 days after parturition. Measurable levels of these oestrogens were present 40 days before parturition. A steady increase in their concentration commenced 20 days before parturition and peak levels of $4.5 \mathrm{ng} / \mathrm{ml}$ oestrone, $300 \mathrm{pg} / \mathrm{ml}$ for oestradiol $-17 \alpha$ and $450 \mathrm{pg} / \mathrm{ml}$ for oestradiol-17 $\beta$ were found just before parturition. The peak levels of all three oestrogens dropped dramatically over the first $24 \mathrm{hr}$ after parturition and, by $48 \mathrm{hr}$, the plasma concentrations had dropped to $<15 \mathrm{pg} / \mathrm{ml}$ for oestrone and for oestradiol- $17 \beta$ and to $<35 \mathrm{pg} / \mathrm{ml}$ for oestradiol-17 $\alpha$.
\end{abstract}

\section{INTRODUCTION}

The work of Kennedy, Kendrick \& Stormont (1957), Liggins, Kennedy \& Holm (1967) and Liggins \& Kennedy (1968) has aroused considerable interest in the rôle of the steroid hormones of fetal and/or placental origin in the initiation of parturition in ruminants. Most of the early estimates for oestrogen levels in the pregnant cow were obtained by biological assay (Szego \& Roberts, 1946; Bitman, Wrenn \& Sykes, 1958; Pope, Jones \& Waynforth, 1965). The values obtained for total oestrogenic activity during late pregnancy ranged from 0.7 to $7.0 \mathrm{ng} / \mathrm{ml}$. Pope et al. (1965) reported that most of the oestrogenic activity was due to oestrone. Using a fluorimetric method for measuring total oestrone, i.e. oestrone conjugated and unconjugated in whole blood samples from pregnant cows, Robinson, Baker, Anastassiadis \& Common (1970) found a marked elevation of oestrone over the period of 4 to 2 weeks before, and up to, the time of parturition. A high mean value of $8.3 \mathrm{ng} / \mathrm{ml}$ was found 5 days before parturition. In those reports, the values presented included the oestrogens

* Contribution No. 480 from the Animal Research Institute. 
present in both the unconjugated and the conjugated state, i.e. a hydrolysis step was included in the methodology. Henricks, Dickey, Hill \& Johnston (1972) have recently reported values for the concentration of the total unconjugated oestrogens present in bovine pregnancy plasma.

This study reports the changes in maternal jugular venous plasma concentration of unconjugated oestrone, oestradiol-17 $\alpha$ and oestradiol-17 $\beta$ in pregnant cows over the period from 40 days before to 6 days after parturition.

\section{MATERIALS AND METHODS}

Daily sampling of the maternal jugular venous blood from four Holstein multiparous cows was begun 40 days before the estimated time of parturition (gestation period taken as 280 days) and continued until 6 days after parturition. Blood samples $(15 \mathrm{ml})$ were collected by needle puncture into heparinized tubes at 08.30 hours. Immediately after collection, the tubes were chilled in iced water, centrifuged, and $2 \cdot 5-\mathrm{ml}$ aliquots of plasma were measured into glass vials which were sealed and kept frozen to $-20^{\circ} \mathrm{C}$ until used for assay.

The time of collection of all the samples was subsequently standardized from the time of parturition taken as Day 0 . As it was impracticable to carry out estimations of oestrone, oestradiol-17 $\alpha$ and oestradiol-17 $\beta$ on all the plasma samples collected for each animal, pooled samples were made for each of the 40 pre-partum to 6 post-partum days. Not all of these pooled daily samples were analysed (see Text-fig. 1). In order to obtain an estimate of the betweenanimal variation and to determine the effect, if any, of the sex of the fetus, estimates were carried out on individual plasma samples taken from each animal on Day 6 before parturition.

\section{Oestrogen determination}

Unconjugated oestrone, oestradiol-17 $\alpha$ and oestradiol-17 $\beta$ were measured by the method of Robertson, Smeaton \& Durnford (1972) using $1 \mathrm{ml}$ plasma. Oestrone and oestradiol-17 $\beta$ were estimated from a standard curve prepared against oestradiol-17 $\beta$ while oestradiol-17 $\alpha$ was measured against a standard curve prepared against oestradiol-17 $\alpha$. The sensitivity of this method has been estimated to be $11 \mathrm{pg}$ for oestrone, $13 \mathrm{pg}$ for oestradiol-17 $\beta$ and $34 \mathrm{pg}$ for oestradiol-17 $\alpha$. All determinations were carried out in duplicate and the values presented have been corrected for procedural losses.

\section{RESULTS}

Plasma oestrogen values

Changes in the concentration of unconjugated oestrone, oestradiol-17 $\alpha$ and oestradiol-17 $\beta$ in the pooled jugular venous plasma samples are shown in Text-fig. 1.

It will be observed that, at 40 days before parturition, there were low, but measurable, levels of unconjugated oestradiol-17 $\beta(25 \mathrm{pg} / \mathrm{ml})$ and that this level was maintained over the period -40 to -19 days before parturition. The concentration of oestradiol-17 $\alpha$ was below the limits of sensitivity of the method 


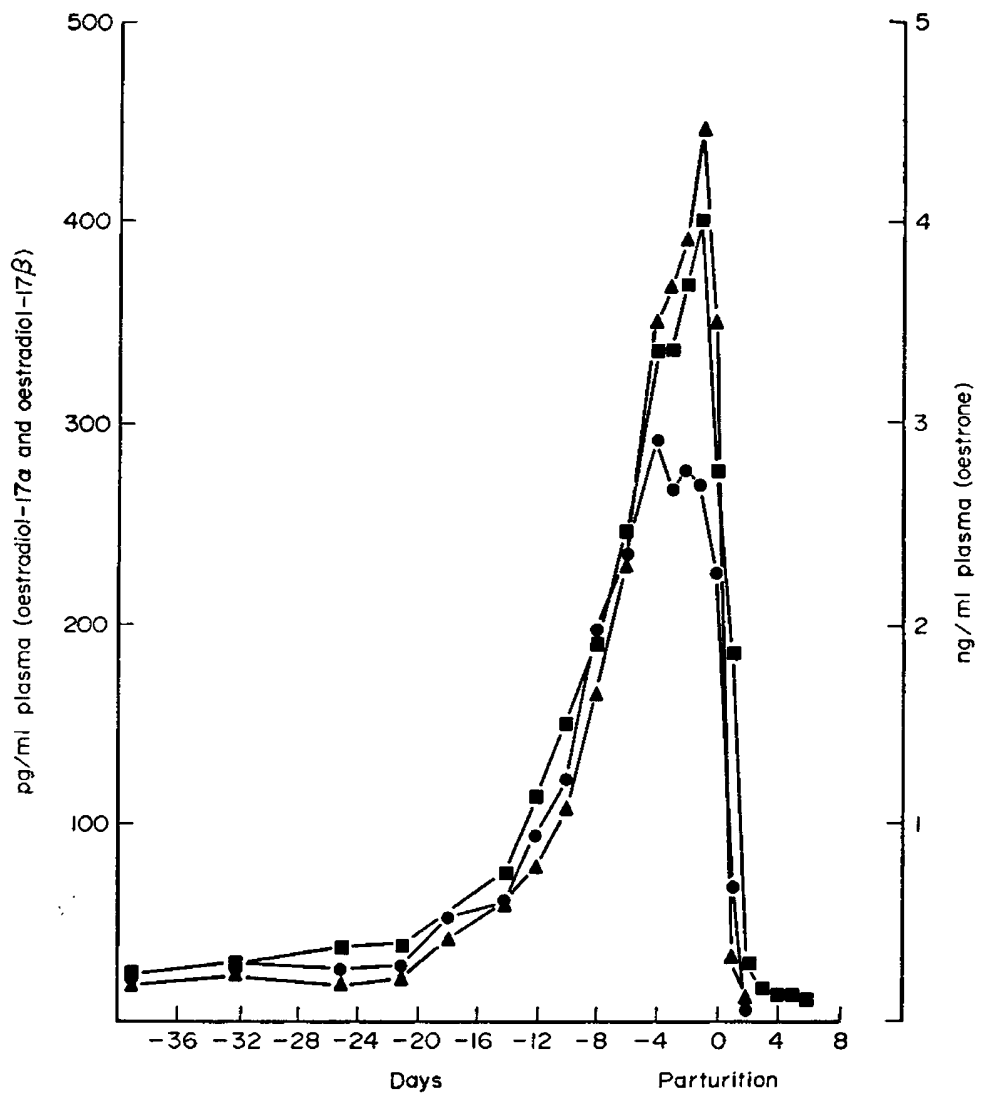

TEXT-FIG. 1. Changes in the maternal jugular venous plasma concentration of unconjugated oestrone $(\boldsymbol{\theta})$, oestradiol-17 $\alpha(\bullet)$ and oestradiol-17 $\beta(\Lambda)$ in relation to the time of parturition in the pregnant cow.

but determinations gave consistent estimates of 12 to $25 \mathrm{pg} / \mathrm{ml}$ over the period of -40 to -21 days. Over the same period, the concentration of oestrone was already at a level of $240 \mathrm{pg} / \mathrm{ml}$ at Day -40 and was rising slowly.

Over the period from the 19th day before parturition to the day of parturition, a parallel rise in the concentration of all the oestrogens occurred with the peak for oestrone at $4 \mathrm{ng} / \mathrm{ml}$, that for oestradiol- $17 \beta$ at $450 \mathrm{pg} / \mathrm{ml}$ and that for oestradiol- $17 \alpha$ at $280 \mathrm{pg} / \mathrm{ml}$. Over most of this period, the concentrations of oestradiol-17 $\alpha$ and of oestradiol-17 $\beta$ were remarkably similar. Over the period -4 to 0 days, however, the oestradiol-17 $\beta$ concentration increased by a further $150 \mathrm{pg} / \mathrm{ml}(50 \%)$ while the oestradiol $-17 \alpha$ reached a plateau and indeed appeared to fall slightly. After parturition, the concentration of oestradiol-17 $\alpha$ and of oestradiol-17 $\beta$ was too low to measure within 2 days and that for oestrone in approximately 3 days. The ratio for the concentration of oestrone to the concentration of oestradiol-17 $\alpha$ or oestradiol- $17 \beta$ remained constant at approximately 10:1 during the period -40 to 0 days, except for the period from -4 days to parturition when the concentration of oestradiol- $17 \alpha$ ceased to rise. 


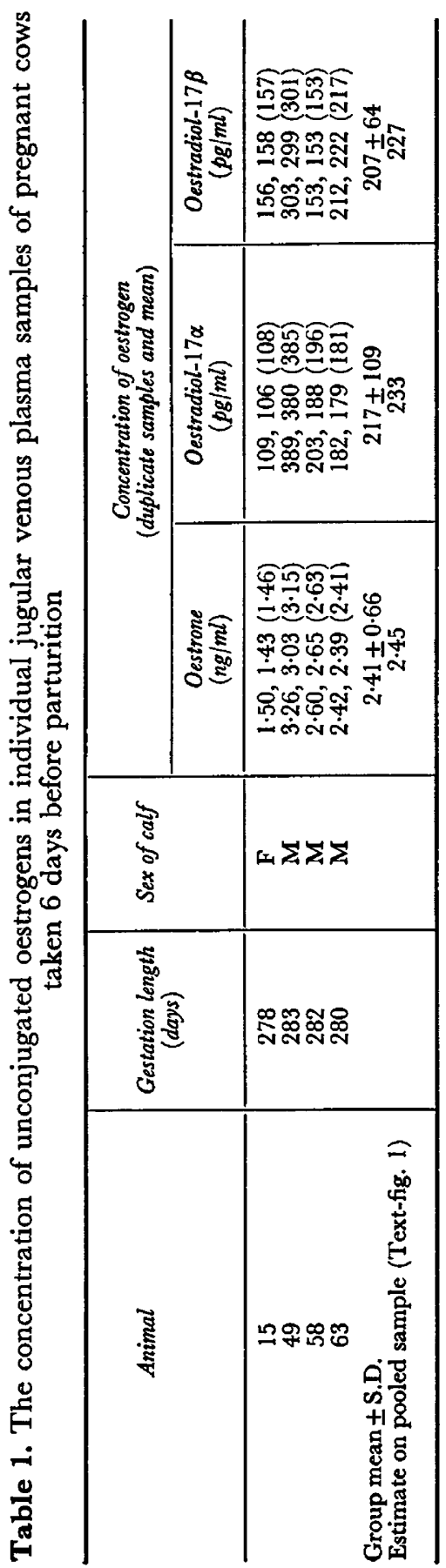


Table 1 presents data on the sex of the calf born and the plasma oestrogen concentrations for individual cows estimated at -6 days. It will be noted that considerable variation existed between individuals with respect to the concentration of the three oestrogens but the ratios between the three oestrogens for each individual cow were relatively constant. From the limited data, it is not possible to determine whether the sex of the fetus influences the plasma oestrogen concentration.

\section{DISCUSSION}

The present results show that by 40 days before parturition, the concentration of unconjugated oestrone in plasma is already relatively high and rising while the levels of unconjugated oestradiol- $17 \alpha$ and oestradiol-17 $\beta$ are approximately ten times lower. A marked rise in the concentration of all the oestrogens commences at about 20 days before parturition and reaches a peak value for oestrone and oestradiol-17 $\beta$ at the time of parturition. Oestradiol-17 $\alpha$ reaches a plateau or indeed may begin falling slightly 5 days before parturition. Following parturition, there is a rapid fall in the plasma concentration of the three oestrogens. There is no prolongation of an elevated oestradiol-17 $\alpha$ concentration such as has been reported in post-partum ewes (Robertson \& Smeaton, 1973). These cows did not ingest their placental membranes. There is no evidence from these data that a further acute increase in the rate of rise of the plasma oestrogens occurs over the last few days of gestation such as has been demonstrated in the sheep (Challis, 1971; Thorburn, Nicol, Bassett, Shutt \& Cox, 1972; Robertson \& Smeaton, 1973) and in the goat (Challis \& Linzell, 1971; Thorburn et al., 1972). However, it should be noted that, because blood samples were taken only once per day at a fixed time, a wide variation in time could exist between the time of the last sample and the time of parturition which could have modified the values obtained for the last two samples before parturition. More frequent sequential sampling on individual animals (over the last 4 to 5 days of gestation) will be required to resolve this point. The time of the observed rise of the unconjugated oestrogens is in agreement with the findings of Robinson et al. (1970) for total oestrone. These workers found that total oestrone values ranged from 3.5 to $13.5 \mathrm{ng} / \mathrm{ml}$ at 5 days before parturition, with a mean of $8.3 \mathrm{ng} / \mathrm{ml}(n=7)$. By comparison, the mean concentration of the unconjugated oestrone found in the present study at this time was 2.9 $\mathrm{ng} / \mathrm{ml}(n=4)$, implying that there may be significant quantities of oestrone present in other chemical forms, i.e. as conjugates. Henricks et al. (1972) found a rise in the concentration of total unconjugated oestrogens over the last 14 days of gestation. No values earlier than 14 days before parturition were measured and it was not therefore possible to determine when this rise began. The mean peak value found by these workers was $2.6 \mathrm{ng} / \mathrm{ml}$ for the total unconjugated oestrogens compared to the value of $4.5 \mathrm{ng} / \mathrm{ml}$ for unconjugated oestrone alone found in the present study. Robinson, Anastassiadis \& Common (1971) examined in more detail the daily whole-blood concentration for total oestrone in seven pregnant cows over the period -6 days before to +4 days after parturition. They reported that before the precipitous drop that occurs 
within 1 day of parturition, the majority of the cows showed some decline in oestrone concentration. This began 2 to 5 days before parturition. While the present mean values for unconjugated oestrone and for oestradiol-17 $\beta$, which continue to rise until just before parturition, are not in agreement with the above findings, the values reported here for oestradiol-17 $\alpha$, which reach a plateau or begin to fall slightly 4 days before parturition, may be related to the observed fall in the total oestrone level.

In the cow, there is a gradual decline in the concentration of maternal plasma progesterone before parturition. Because this decline is gradual, it is difficult to determine with precision just when it occurs but the consensus of opinion is that it commences at about 40 days before parturition (Pope et al., 1965; Stabenfeldt, Osburn \& Ewing, 1970; Donaldson, Bassett \& Thorburn, 1970; Robertson, 1972). This fall in plasma progesterone in the pregnant cow would appear, therefore, to precede the rise in plasma unconjugated oestrogens.

The variability of the oestrogen levels for individual cows (Table 1) as determined at -6 days before parturition precludes making any firm judgement on the effect of the sex of the fetus on the oestrogen concentrations but it seems likely that if such differences do exist they must be small.

The relationship between the maternal plasma levels of cortisol, progesterone, oestrogens and the initiation of parturition in the sheep and in the goat has been reviewed by Liggins, Grieves, Kendall \& Knox (1972), Thorburn et al. (1972), and by Bedford, Challis, Harrison \& Heap (1972) and the evidence for progesterone and for oestrogen suggests that a similar quantitative if not temporal relationship holds for the cow.

The relevance of oestrogens in the development of the mammary gland during gestation should be considered, bearing in mind that the requirements for the development of the mammary gland of the virgin heifer during gestation may be different from that of the adult cow lactating through most of pregnancy. The general area of the effect of steroids on mammary gland development has been reviewed by Cowie (1971) and the general finding from empirical experiments carried out on cows and on goats is that a combination of progesterone and oestrogen would appear to yield the best functional development in the non-pregnant animal. In the pregnant cow, it is difficult to postulate a rôle for oestrogens in mammary growth during the major period of pregnancy unless the cells of the mammary gland are sensitive to concentrations of 250 $\mathrm{pg} / \mathrm{ml}$ or less of oestrone, or to $25 \mathrm{pg} / \mathrm{ml}$ or less of oestradiol- $17 \beta$. The finding of plasma concentrations of oestrone which are ten times greater than those for oestradiol- $17 \beta$ raises the question of whether oestrone is as important biologically in the cow as oestradiol-17 $\beta$.

\section{AGKNOWLEDGMENTS}

I wish to thank Mr R. Durnford for highly skilled technical assistance, Dr B. V. Caldwell for the anti-serum and Dr D. S. Layne for the $\left[{ }^{3} \mathrm{H}\right]$ oestradiol-17 $\alpha$ used in the above assays. 


\section{REFERENCES}

Bedford, C. A., Ghallis, J. R. G., Harrison, F. A. \& Heap, R. B. (1972) The rôle of oestrogens and progesterone in the onset of parturition in various species. F. Reprod. Fert., Suppl. 16, 1.

Brtman, J., WrenN, T. R. \& Syxes, J. F. (1958) Estrogen determination in blood and body fuids of cattle. In: Proc. 3rd Symp. Reproduction and Infertility. Ed. F. X. Gassner. Pergamon Press, New York.

Ghallis, J. R. G. (1971) Sharp increase in free circulating oestrogens immediately before parturition in sheep. Nature, Lond. 229, 20.

Ghallis, J. R. G. \& Linzell, J. L. (1971) The concentration of total unconjugated oestrogens in the plasma of pregnant goats. F. Reprod. Fert. 26, 401.

CowIE, A. T. (1971) Infiuences of hormones on mammary growth and milk secretion. In: Lactation. Ed. I. R. Falconer. Butterworth, London.

Donaldson, L. E., Bassett, J. M. \& Thorburn, G. D. (1970) Peripheral plasma progesterone concentration of cows during puberty, oestrous cycles, pregnancy and lactation, and the effects of undernutrition or exogenous oxytocin on progesterone concentration. $\mathcal{F}$. Endocr. 48, 599.

Henricks, D. M., Dickey, J. F., Hill, J. R. \& Johnston, W. E. (1972) Plasma estrogen and progesterone levels after mating, and during late pregnancy and postpartum in cows. Endocrinology 90, 1336.

Kennedy, P. G., Kendrick, J. W. \& Stormont, G. (1957) Adenohypophyseal aplasia, an inherited defect associated with abnormal gestation in Guernsey cattle. Cornell Vet. 47, 160.

Liggins, G. C., Grieves, S. A., Kendale, J. Z. \& Knox, B. S. (1972) The physiological rôles of progesterone, oestradiol-17 $\beta$ and prostaglandin $\mathrm{F}_{2 \alpha}$ in the control of ovine parturition. $\mathcal{F}$. Reprod. Fert., Suppl. 16, 85.

Liggins, G. C. \& KenNedy, P. C. (1968) Effects of electrocoagulation of the foetal lamb hypophysis on growth and development. F. Endocr. 40,371.

LigGins, G. C., KenNedy, P. C. \& Holm, L. W. (1967) Failure of initiation of parturition after electrocoagulation of the pituitary of the foetal lamb. Am. F. Obstet. Gynec. 98, 1080.

Pope, G. S., Jones, H. E. H. \& Waynforth, H. B. (1965) Oestrogens in the blood of the cow. $\mathcal{F}$. Endocr. 33, 385.

Robertson, H. A. (1972) Sequential changes in plasma progesterone in the cow during the estrous cycle, pregnancy, at parturition and postpartum. Can. F. Anim. Sci. 52, 645.

Robertson, H. A. \& Smeaton, T. G. (1973) The concentration of unconjugated oestrone, oestradiol$17 \alpha$ and oestradiol- $17 \beta$ in the maternal plasma of the pregnant ewe in relation to the initiation of parturition and lactation. J. Reprod. Fert. 35, 461.

Robertson, H. A., Smeaton, T. G. \& Durnford, R. (1972) A method for the extraction, separation and estimation of unconjugated estrone, estradiol-17 $\alpha$ and estradiol-17 $\beta$ in plasma. Steroids, 20,651 .

Robinson, R., Anastassiadis, P. A. \& Common, R. H. (1971) Estrone concentrations in the peripheral blood of pregnant cows. II. Values around parturition. J. Dairy Sci. 54, 1832.

Robinson, R., Baker, R. D., Anastassiadis, P. A. \& Common, R. H. (1970) Estrone concentrations in the peripheral blood of pregnant cows. F. Dairy Sci. 53, 1592.

Stabenfeldt, G. H., Osburn, B. I. \& Ewing, L. L. (1970) Peripheral plasma progesterone levels in the cow during pregnancy and parturition. Am. F. Physiol. 218, 571.

Szego, G. M. \& Roberts, S. (1946) The nature of circulating estrogen. Proc. Soc. exp. Biol. Med. 61 161.

Thorburn, G. D., Nicol, D. H., Bassetr, J. M., Shutt, D. A. \& Cox, R. I. (1972) Parturition in the goat and sheep: changes in corticosteroids, progesterone, oestrogens and prostaglandin $F . \mathcal{F}$. Reprod. Fert., Suppl. 16, 61 . 